\title{
Editorial Note: Multimedia communications and Internet of Things
}

Published online: 2 August 2019

(C) Springer Science+Business Media, LLC, part of Springer Nature 2019

Multimedia Tools and Applications gratefully acknowledges the editorial work of the scholars listed below on the special issue entitled, "Multimedia communications and Internet of Things."

Of 44 papers submitted to this issue, 13 were eventually accepted after a stringent peer-review process.

\section{Corresponding Guest Editor}

\section{Dr. Pourya Shamsolmoali}

Shanghai Jiao Tong University, China

Email: pshams@sjtu.edu.cn

\section{Guest Editors}

Dr. Huiyu Zhou

Queen's University Belfast, UK

Email: h.zhou@ecit.qub.ac.uk

\section{Prof. Zhiyong (Zeroun) Zhang}

Henan University of Science \& Technology, China

Email: xidianzzy@126.com

Publisher's note Springer Nature remains neutral with regard to jurisdictional claims in published maps and institutional affiliations. 